\title{
Screening of Luzula species native to the Carpathian Basin for anti-inflammatory activity and bioactivity-guided isolation of compounds from Luzula luzuloides (Lam.) Dandy \& Wilmott
}

\author{
Barbara Tóth ${ }^{\text {a }}$, Fang-Rong Chang b, c, d, Tsong-Long Hwang e, f, g, k, 1, Ádám Szappanos ${ }^{\text {h }}$, Attila Mándi ${ }^{\text {h }}$, \\ Attila Hunyadi ${ }^{\text {a }}$, Tibor Kurtán ${ }^{\text {h }}$, Gusztáv Jakab ${ }^{\mathrm{i}}$, Judit Hohmann ${ }^{\mathrm{a}, \mathrm{j}}$, Andrea Vasas ${ }^{\mathrm{a}, *}$ \\ a Department of Pharmacognosy, University of Szeged, 6720 Szeged, Hungary \\ ${ }^{\mathrm{b}}$ Graduate Institute of Natural Products, Kaohsiung Medical University, 807 Kaohsiung, Taiwan \\ ${ }^{c}$ Research Center for Environmental Medicine, Kaohsiung Medical University, 807 Kaohsiung, Taiwan \\ ${ }^{\mathrm{d}}$ Department of Marine Biotechnology and Resources, National Sun Yat-sen University, 804 Kaohsiung, Taiwan \\ ' Graduate Institute of Natural Products, Chang Gung University, 333 Taoyuan, Taiwan \\ ${ }^{\mathrm{f}}$ Research Center for Industry of Human Ecology, Chang Gung University of Science and Technology, 333 Taoyuan, Taiwan \\ ${ }^{g}$ Department of Anesthesiology, Chang Gung Memorial Hospital, 333 Taoyuan, Taiwan \\ ${ }^{\mathrm{h}}$ Department of Organic Chemistry, University of Debrecen, 4032 Debrecen, Hungary \\ ${ }^{i}$ Institute of Environmental Sciences, Faculty of Water and Environmental Management, Szent István University, 5540 Szarvas, Hungary \\ j Interdisciplinary Centre of Natural Products, University of Szeged, 6720 Szeged, Hungary \\ ${ }^{\mathrm{k}}$ Research Center for Chinese Herbal Medicine, Chang Gung University of Science and Technology, 333 Taoyuan, Taiwan \\ ${ }^{1}$ Graduate Institute of Health Industry Technology, Chang Gung University of Science and Technology, 333 Taoyuan, Taiwan
}

\section{A R T I C L E IN F O}

\section{Article history:}

Received 28 October 2016

Received in revised form 1 December 2016

Accepted 3 December 2016

Available online $\mathrm{xxx}$

Keywords:

Juncaceae

Luzula luzuloides

Phenanthrenes

Flavonoids

Anti-inflammatory activity

Electronic circular dichroism

\section{A B S T R A C T}

The present study focused on the anti-inflammatory screening of Luzula species native to the Carpathian Basin and bioactivity-guided isolation of compounds of Luzula luzuloides (Lam.) Dandy \& Wilmott. The anti-inflammatory properties of extracts with different polarity prepared from Luzula species were determined. Among them, the $\mathrm{CH}_{2} \mathrm{Cl}_{2}$-soluble fraction of L. luzuloides possessed strong inhibitory effects on superoxide anion generation $(99.39 \pm 0.37 \%)$ and elastase release $(114.22 \pm 3.13 \%)$ in fMLP/CB-induced human neutrophils at concentration of $10 \mu \mathrm{g} / \mathrm{mL}$. From this fraction, six compounds (1-6) were isolated by the combination of different chromatographic methods. The structures of the compounds were determined by means of MS, 1D and 2D NMR spectroscopy. The results allowed the identification of the new 1,6-dihydroxy-2-keto-1,7-dimethyl-8-vinyl-1,2-dihydrophenanthrene (1) from the plant, named luzulin A. Chiral HPLC and HPLC-ECD analysis revealed that 1 possesses low enantiomeric excess and TDDFT-ECD calculations afforded the configurational assignment of the separated enantiomers. Three known phenanthrenes [juncuenin B (2), dehydrojuncuenin B (3) and juncusol (4)] and two flavonoids [apigenin (5) and luteolin (6)] were also isolated. The anti-inflammatory activity of the isolated compounds was tested and $\mathrm{IC}_{50}$ values were determined. This was the first time that phenanthrenes were detected in a Luzula species. The oxidative transformation of juncuenin B (3) led to the isolation of its possible biometabolites, namely luzulin A (1), dehydrojuncuenin B (4), and juncuenin D (7). The isolated compounds (1-4) confirm that besides flavonoids, phenanthrenes could also serve as chemotaxonomic markers for Luzula species and prove the close relationship of Juncus and Luzula genus.

(C) 2016 Published by Elsevier Ltd.

\section{Introduction}

The family Juncaceae includes $>500$ species, which are distributed worldwide. Juncus and Luzula are the two largest genera of the family Juncaceae, comprising approximately 340 and 115 species, respectively $[1,2]$. Among them up to 45 species are native to the Carpathian Basin. Although traditional use of plants belonging to the genus Luzula has not been reported yet, several Juncus species (e.g. J. effusus and J. acutus) are used in oriental folk medicine for the treatment of cold, fever, anxiety or insomnia [3-5].

Despite of the comprehensive research focused on Juncaceae family, until now only species belonging to the genus Juncus were inves-

\footnotetext{
* Corresponding author.

Email address: vasasa@pharmacognosy.hu (A. Vasas)
}

tigated extensively [6-9]. There is a significant lack of information with regards to chemical constituents of the plants belonging to the genus Luzula. Hitherto only the flavonoid components of Luzula species were studied. Luteolin and luteolin-7-O-glucoside were isolated by the use of preparative paper chromatography from $L$. sylvatica [10]. Williams et al. identified several flavonoids by using TLC, comparing their $R_{\mathrm{f}}$ values and colors with standards, and luteolin and luteolin 7-O-glucoside were detected from all of the investigated Luzula samples (L. arcuata, L. campestris, L. confusa, L. forsteri, L. lactea, L. multiflora, L. nivea, L. nodulosa, L. nutans, L. pilosa, L. spicata and $L$. sylvatica) [11]. Quercetin, procyanidin and other luteolin derivatives (luteolin 5-methyl ether, luteolin 5-methyl ether 7-O-glucoside) were also identified in some species [11]. Therefore, flavonoids are considered to be the main secondary metabolites, and one of the most characteristic components of Luzula species. 
Previously benzocoumarins, diterpenoids, cycloartane triterpenes, carotenoids, phenanthrenes, flavonoids, and other phenolic compounds were isolated from Juncus species [12-16]. Apart from flavonoids, phenanthrenes and 9,10-dihydrophenanthrenes are the most specific chemical constituents of the family. To date $>90$ novel monomeric and 8 dimeric phenanthrenes have been identified from Juncaceae species [6-9]. Phenanthrenes are considered to be important taxonomic markers, because of their limited occurrence. Moreover, vinylated phenanthrenes have been reported only from species of the family Juncaceae [6-9]. Phenanthrenes occurring in plants have drawn considerable interest from the aspect of natural product drug discovery because of the wide range of their potentially valuable biological activities, e.g. cytotoxic, antimicrobial and anti-inflammatory activities [6-9].

Juncus effusus has been used in the traditional oriental medicine as a remedy for inflammation, therefore, isolated phenanthrenes from the plant were also tested for their anti-inflammatory activity by the inhibition of LPS-induced NO production on RAW 264.7 cells and compounds showed promising effect [17-20]. By the use of this assay a strong anti-inflammatory activity was detected in case of effususin $\mathrm{B}\left(\mathrm{IC}_{50}=7.42 \pm 0.50 \mu \mathrm{M}\right)$, compared to the positive control quercetin $\quad\left(\mathrm{IC}_{50}=6.63 \pm 0.28 \mu \mathrm{M}\right) \quad$ [17]. 8-Hydroxymethyl-2-hydroxy-1-methyl-5-vinyl-9,10-dihydrophenanthrene

$\left(\mathrm{IC}_{50}=14.42 \pm 2.82 \mu \mathrm{M}\right), \quad 5$-(1-methoxyethyl)-1-methylphenanthrene-2,7-diol $\quad\left(\mathrm{IC}_{50}=11.10 \pm 1.67 \mu \mathrm{M}\right), \quad$ effusol $\left(\mathrm{IC}_{50}=15.13 \pm 0.54 \mu \mathrm{M}\right)$, dehydroeffusol $\left(\mathrm{IC}_{50}=12.69 \pm 1.68 \mu \mathrm{M}\right)$, dehydroeffusal $\left(\mathrm{IC}_{50}=10.50 \pm 0.90 \mu \mathrm{M}\right), 2,7$-dihydroxy-5-hydroxymethyl-1-methyl-9,10-dihydrophenathrene

$\left(\mathrm{IC}_{50}=16.06 \pm 1.18 \mu \mathrm{M}\right), \quad$ 5-hydroxymethyl-1-methylphenanthrene-2,7-diol $\quad\left(\mathrm{IC}_{50}=16.30 \pm 2.41 \mu \mathrm{M}\right), \quad$ dehydrojuncusol $\left(\mathrm{IC}_{50}=15.57 \pm 1.08 \mu \mathrm{M}\right)$, and the mixture of 2,7-dihydroxy-1,8-dimethyl-5-vinyl-9,10-dihydrophenanthrene and juncusol $\left(\mathrm{IC}_{50}=13.65 \pm 1.40 \mu \mathrm{M}\right)$ also had remarkable activities in comparison with the positive control quercetin [18].

Juncutol displayed noteworthy anti-inflammatory activity by the inhibition of the iNOS protein expression in LPS-stimulated RAW 264.7 cells. The iNOS level was reduced to $11.2 \pm 13.1 \%$ from $100 \%$ after treating with $10 \mu \mathrm{M}$ juncutol [19]. Dehydrojuncusol and its dimer, 8,8'-bidehydrojuncusol were also assayed by the abovementioned method. According to the immunoblot analysis, the effect of dehydrojuncusol on the iNOS protein $(41.0 \pm 8.0 \%$ inhibition at $10 \mu \mathrm{M})$ decreased dramatically after dimerization $(<12.0 \%$ inhibition at $10 \mu \mathrm{M})[20]$.

The anti-inflammatory activity of flavonoids is well-studied, but in some cases the mechanism of action of these compounds is not completely established [21,22]. Apigenin and luteolin inhibited the LPS induced NO-production on RAW 264.7 macrophages with $\mathrm{IC}_{50}$ values of $23 \mu \mathrm{M}$ and $27 \mu \mathrm{M}$, respectively. While luteolin reduced the iNOS expression and interestingly increased the enzyme activity in a dose-dependent manner, apigenin inhibited the iNOS and COX-2 expression in LPS-activated RAW264.7 cells, but had no effect on the iNOS enzyme activity $[23,24]$. Both apigenin and luteolin inhibited significantly the TNF $\alpha$-induced NF- $\mathrm{KB}$ activation on KF 8 cells. Moreover, their anti-inflammatory activity was confirmed in vivo by the inhibition of carrageenan-induced paw inflammation on mice [25].

The purposes of the present study were to investigate the anti-inflammatory properties of Luzula species, and to perform an activity-guided fractionation of Luzula luzuloides in order to isolate the compounds responsible for this effect.

\section{Experimental}

\subsection{General}

Normal phase vacuum liquid chromatography (VLC) was carried out on silica gel (Kieselgel $\mathrm{GF}_{254}, 15 \mu \mathrm{m}$, Merck). LiChroprep RP-18 (40-63 $\mu \mathrm{m}$, Merck) stationary phase was used for reversed-phase VLC. Column chromatography (CC) was performed on polyamide (MP Biomedicals). Sephadex LH-20 (25-100 $\mu \mathrm{m}$, Pharmacia Fine Chemicals) was used for gel filtration. Preparative thin-layer chromatography (preparative TLC) was carried out on silica gel $60 \mathrm{~F}_{254}$ plates (Merck).

NMR spectra were recorded in $\mathrm{CD}_{3} \mathrm{OD}$ and DMSO- $d_{6}$ on a Bruker Avance DRX 500 spectrometer at $500 \mathrm{MHz}\left({ }^{1} \mathrm{H}\right)$ and $125 \mathrm{MHz}\left({ }^{13} \mathrm{C}\right)$. The signals of the deuterated solvents were taken as reference. Two-dimensional (2D) experiments were performed with a standard Bruker software. In the COSY, HSQC and HMBC experiments, gradient-enhanced versions were applied. The high resolution MS spectra were acquired on a Thermo Scientific Q-Exactive Plus orbitrap mass spectrometer equipped with ESI ion source in positive ionization mode. The resolution was over $1 \mathrm{ppm}$. The data were acquired and processed with the MassLynx software. ECD spectra was recorded on a J-810 spectropolarimeter.

HPLC-ECD analysis: chiral HPLC separation was performed with a JASCO HPLC system using Chiralpak IA column with $250 \mathrm{~mm} \times 4.6 \mathrm{~mm}$ i.d., $5 \mu \mathrm{m}$ (Daicel, Chemical Industries, Ltd.), and $n$-hexane-propan-2-ol eluent at a flow rate of $1.0 \mathrm{~mL} / \mathrm{min}$ was used. HPLC-UV and OR chromatograms were recorded with JASCO MD-910 multiwavelength and OR-2090 Plus chiral detector, respectively. The on-line ECD and UV spectra were measured simultaneously by stopping the flow at the UV absorption maximum of each peak. The values of the ECD ellipticity $(\phi)$ were not corrected for the concentration. Three consecutive scans were recorded and averaged for an HPLC-ECD spectrum with standard sensitivity, $2 \mathrm{~nm}$ bandwidth and $1 \mathrm{~s}$ response. The background HPLC-ECD spectrum of the eluent was recorded in the same way.

\subsection{Plant material}

Plants (Luzula campestris (L.) DC., L. forsteri (Sm.) DC., L. luzuloides (Lam.) Dandy \& Wilmott, L. sudetica (Willd.) Schult., L. sylvatica (Huds.) Gaudin) were collected during the flowering period between June and September 2014, in several regions of the Carpathian Basin (Hungary, Croatia and Romania). Botanical identification of the plant material was performed by Gusztáv Jakab (Institute of Environmental Sciences, Szent István University, Szarvas, Hungary) and voucher specimens (No. 869-873) have been deposited at the Department of Pharmacognosy, University of Szeged, Szeged, Hungary.

\subsection{Preparation of plant samples}

For the anti-inflammatory screening assay, extracts were prepared from $20 \mathrm{~g}$ of air-dried plant materials (whole plant, roots and aerial parts) with $5 \times 100 \mathrm{~mL}$ of $\mathrm{MeOH}$ with the use of ultrasonic bath $(5 \times 15 \mathrm{~min})$. After filtration, the solutions were evaporated to dryness under reduced pressure. The residues were dissolved in $50 \mathrm{~mL}$ of $50 \%$ aqueous $\mathrm{MeOH}$ and subjected to solvent-solvent partition between $n$-hexane $(3 \times 100 \mathrm{~mL})$ (extracts A), dichloromethane $(3 \times 100 \mathrm{~mL})$ (extracts $\mathrm{B})$, and EtOAc $(3 \times 100 \mathrm{~mL})$ (extracts $\mathrm{C})$, and the remaining $\mathrm{H}_{2} \mathrm{O}$ extracts gave extracts $\mathrm{D}$. 


\subsection{Extraction and isolation}

The air-dried whole plant of $L$. luzuloides $(480 \mathrm{~g}$ ) was percolated with $\mathrm{MeOH}(20 \mathrm{~L})$ at room temperature. The crude methanol extract was concentrated under reduced pressure (76 g) and subjected to solvent-solvent partitioning with $\mathrm{CH}_{2} \mathrm{Cl}_{2}(2.5 \mathrm{~L})$. After evaporation, the $\mathrm{CH}_{2} \mathrm{Cl}_{2}$ fraction $(4.95 \mathrm{~g})$ was chromatographed on a polyamide column with mixtures of $\mathrm{MeOH}$ and $\mathrm{H}_{2} \mathrm{O}$ [1:1, 4:1 (1 L and $4 \mathrm{~L}$, respectively); each eluent was collected as a fraction]. The fraction obtained from the polyamide column with methanol-water 4:1 (1.10 g) was further chromatographed by VLC on silica gel with a gradient system of cyclohexane-EtOAc-EtOH [from 9:1:0 to 5:5:1 (300 mL/eluent), and finally with $\mathrm{EtOH}(200 \mathrm{~mL})$; volume of collected fractions was $20 \mathrm{~mL}$ ] to yield twelve major fractions $(1-12)$.

From fraction $1(9.2 \mathrm{mg})$ compound $2(5.2 \mathrm{mg})$ was crystallized. Fraction 4 (31.3 mg) was purified by Sephadex LH-20 gel chromatography using $\mathrm{MeOH}$ as eluent $[(100 \mathrm{~mL})$; volume of collected fractions was $2 \mathrm{~mL}$ ] to afford four subfractions (4/1-4). Compound 1 $(3.0 \mathrm{mg})$ was purified from subfraction $4 / 1$ by preparative TLC using $n$-hexane-EtOAc (7:3) as solvent system. Subfraction 4/3 (14.1 mg) was also purified by preparative TLC on silica gel, with cyclohexane-EtOAc-MeOH (20:10:1) as solvent system to afford compound $3(5.1 \mathrm{mg})$. Compound $4(3.2 \mathrm{mg})$ was crystallized from subfraction $4 / 4$. Fraction $6(25.1 \mathrm{mg})$ was separated by RP-VLC, with a gradient system of $\mathrm{MeOH}-\mathrm{H}_{2} \mathrm{O}$ [from 4:6 to 9:1 (150 mL/eluent), and finally with $\mathrm{MeOH}(100 \mathrm{~mL})$; volume of collected fractions was $10 \mathrm{~mL}]$ to yield five subfractions $(6 / 1-5)$. Compound $5(9.0 \mathrm{mg})$ was crystallized from subfraction $6 / 2$. Furthermore, compound $6(7.1 \mathrm{mg})$ was crystallized from fraction 7.

\subsubsection{Luzulin A (1)}

Amorphous solid; $[\alpha]_{\mathrm{D}}{ }^{26} 0(c 0.1, \mathrm{MeOH}) ;{ }^{1} \mathrm{H}$ and ${ }^{13} \mathrm{C}$ NMR data, see Table 2; (+)-HRESIMS $\mathrm{m} / \mathrm{z} 281.1175[\mathrm{M}+\mathrm{H}]^{+}$(calcd for $\left.\mathrm{C}_{18} \mathrm{H}_{17} \mathrm{O}_{3}, 281.1177\right) .25 \%$ ee with an excess of $(S)-\mathbf{1}$.

$(R)-1: \quad t_{\mathrm{R}}=4.88 \mathrm{~min}$ on Chiralpak IA column ( $n$-hexane-propan-2-ol, 8:2); HPLC-ECD \{n-hexane-propan-2-ol, $8: 2, \lambda[\mathrm{nm}](\phi)\}: 424(2.30), 376(-4.49), 312(-3.51), 287(0.10)$, 266 (-2.52), 244sh (3.92), 229 (5.17), 204 (-7.81).

$(S)-1: \quad t_{\mathrm{R}}=5.41 \mathrm{~min}$ on Chiralpak IA column (n-hexane-propan-2-ol, 8:2); HPLC-ECD \{n-hexane-propan-2-ol, 9:1, $\lambda[\mathrm{nm}](\phi)\}: 424(-2.96), 374$ (4.26), 312 (2.68), $287(-1.23)$, 268 (1.53), 244sh (-7.57), 227 (-8.36), 204 (5.46).

\subsection{Oxidation of juncuenin B}

$50.0 \mathrm{mg}$ of juncuenin $\mathrm{B}(3)$ was dissolved in $\mathrm{CH}_{3} \mathrm{CN}-\mathrm{H}_{2} \mathrm{O}(9: 1$, $50 \mathrm{~mL}$ ). 2 eq. [bis(trifluoroacetoxy)iodo]benzene (PIFA) $(106.1 \mathrm{mg}$ ) was added to the solution in a careful manner to prevent sudden boiling. The reaction was monitored by TLC using cyclohexane-EtOAc-EtOH $(20: 10: 1)$ as solvent system. After $30 \mathrm{~min}$ of stirring at room temperature, all of the starting material, juncuenin B (3) was converted. The mixture was cooled down in an ice bath, and evaporated at room temperature.

\subsection{Separation of the oxidative products of juncuenin $B$}

The concentrated mixture was chromatographed by VLC on silica gel $(25 \mathrm{~mm} \times 100 \mathrm{~mm})$ with a gradient system of $\mathrm{CH}_{2} \mathrm{Cl}_{2}$-acetone [from 99:1 to 7:3 (200 mL/eluent), and finally with $\mathrm{MeOH}(150 \mathrm{~mL})$; volume of collected fractions was $20 \mathrm{~mL}$ ] to yield seven major fractions (1-7). Dehydrojuncuenin B (4) $(8.9 \mathrm{mg})$ was purified from fraction 2 after gel filtration on Sephadex $\mathrm{LH}-20$ using $\mathrm{MeOH}-\mathrm{CH}_{2} \mathrm{Cl}_{2}$ (3:1) as eluent $[(60 \mathrm{~mL})$; volume of collected fractions was $3 \mathrm{~mL}]$. Fraction 4 was further separated by gel filtration on Sephadex LH-20 using $\mathrm{MeOH}$ as eluent $[(50 \mathrm{~mL})$; volume of collected fractions was $2 \mathrm{~mL}$ ] to afford three subfractions (4/1-3). From subfraction $4 / 2$ luzulin A (1) $(8.1 \mathrm{mg})$ was obtained by the use of preparative TLC using toluene-acetone (8:2) as solvent system. Juncuenin D (7) $(11.2 \mathrm{mg})$ was isolated from fraction 6 after gel filtration on Sephadex LH-20 using $\mathrm{MeOH}-\mathrm{CH}_{2} \mathrm{Cl}_{2}(3: 1)$ as eluent [ $(50 \mathrm{~mL})$; volume of collected fractions was $2 \mathrm{~mL}$ ]. The compounds were identified according to their TLC patterns and the comparison of their ${ }^{1} \mathrm{H}$ NMR spectrum with literature data [5].

\subsection{Preparation of human neutrophils}

Blood was taken from healthy human donors (20-30 years old) by venipuncture using a protocol approved by the Institutional Review Board at Chang Gung Memorial Hospital. Neutrophils were isolated using a standard method as previously described [26,27]. The cells were obtained from peripheral blood according to the standard method of dextran sedimentation, followed by centrifugation in a Ficoll-Hypaque gradient and the hypotonic lysis of the erythrocytes. The purified neutrophils contained $>98 \%$ of viable cells, as determined by Trypan blue exclusion, and were suspended in calcium-free HBSS at $4{ }^{\circ} \mathrm{C}$ before used.

\subsection{Measurement of superoxide generation}

SOD inhibition was measured by reduction of ferricytochrome $c$ $[26,27]$. Neutrophils $\left(6 \times 10^{5}\right.$ cells $\left./ \mathrm{mL}\right)$ in $0.5 \mathrm{mg} / \mathrm{mL}$ ferricytochrome $c$ and $1 \mathrm{mM} \mathrm{Ca}^{2+}$ were equilibrated at $37^{\circ} \mathrm{C}$ for 2 min and then incubated with drugs for $5 \mathrm{~min}$. The cells were activated using formyl-methionyl-leucyl-phenylalanine (fMLP, $100 \mathrm{nM}$ )/cytochalasin B (CB, $1 \mu \mathrm{g} / \mathrm{mL}$ ) for $10 \mathrm{~min}$. The absorbance was continuously monitored at $550 \mathrm{~nm}$ using a double-beam, six-cell positioned spectrophotometer with constant stirring (Hitachi U-3010, Tokyo, Japan). Calculations were based on the differences in absorbance with and without SOD $(100 \mu / \mathrm{mL})$ divided by the extinction coefficient for the reduction of ferricytochrome $c(\varepsilon=21.1 / \mathrm{mM} / 10 \mathrm{~mm})$.

\subsection{Measurement of elastase release}

The degranulation of azurophilic granules was determined by elastase release as described previously [26,27]. Neutrophils $\left(6 \times 10^{5} / \mathrm{mL}\right)$ were equilibrated in $\mathrm{MeO}$-Suc-Ala-Ala-Pro-Val- $p$-nitroanilide $(100 \mu \mathrm{M})$, an elastase substrate, at $37^{\circ} \mathrm{C}$ for $2 \mathrm{~min}$ and then incubated with drugs for $5 \mathrm{~min}$. The cells were activated using fMLP $(100 \mathrm{nM})$ in the presence of $\mathrm{CB}(0.5 \mu \mathrm{g} / \mathrm{mL})$, and changes in the absorbance at $405 \mathrm{~nm}$ were continuously measured to monitor elastase release. The results are expressed as a percentage of elastase release in the fMLP/ CB-activated, drug-free control system.

\subsection{Statistical methods}

Results of the anti-inflammatory assays were expressed as means \pm S.E.M. Statistical analysis using Student's $t$-test was performed with SigmaPlot (Systat Software, San Jose, CA, USA). A value of $P<0.05$ was considered statistically significant. 


\subsection{Computational section}

Mixed torsional/low-frequency mode conformational searches were carried out by means of the Macromodel 9.9.223 software using the Merck Molecular Force Field (MMFF) with an implicit solvent model for $\mathrm{CHCl}_{3}$ [28]. Geometry reoptimizations were carried out at the B3LYP/6-31G(d) level in vacuo, the B97D/TZVP [29,30] and the CAM-B3LYP/TZVP [31,32] levels with the PCM solvent model for $\mathrm{CHCl}_{3}$. TDDFT ECD calculations were run with various functionals (B3LYP, BH\&HLYP, CAM-B3LYP, PBE0) and the TZVP basis set as implemented in the Gaussian 09 package with the same or no solvent model as in the preceding DFT optimization step [33]. ECD spectra were generated as sums of Gaussians with $3000 \mathrm{~cm}^{-1}$ widths at half-height (corresponding to ca. $41 \mathrm{~nm}$ at $370 \mathrm{~nm}$ ), using dipole-velocity-computed rotational strength values [34]. Boltzmann distributions were estimated from the ZPVE-corrected B3LYP/6-31G(d) energies in the gas-phase calculations and from the B97D/TZVP and CAM-B3LYP/TZVP energies in the solvated ones. The MOLEKEL software package was used for visualization of the results [35-37].

\section{Results and discussion}

In the course of our screening study, the anti-inflammatory activities of 5 species of the Luzula genus native to the Carpathian Basin were evaluated. The results of the assays are listed in Table 1. Extracts were prepared with methanol from whole plants of $L$. campestris, L. forsteri, L. luzuloides and L. sudetica. The plant mater-

\section{Table 1}

Inhibitory effects of extracts with different polarity from Luzula species on superoxide anion generation and elastase release by human neutrophils in response to $\mathrm{FLP} / \mathrm{CB}$ at concentration $10 \mu \mathrm{g} / \mathrm{mL}$.

\begin{tabular}{|c|c|c|c|c|}
\hline Species & Fraction & $\begin{array}{l}\text { Yield } \\
(\mathrm{w} / \mathrm{w} \\
\%)\end{array}$ & $\begin{array}{l}\text { Superoxide anion } \\
\text { inhibition }(\%)\end{array}$ & $\begin{array}{l}\text { Elastase inhibition } \\
(\%)\end{array}$ \\
\hline \multirow{4}{*}{$\begin{array}{l}\text { Luzula campestris }(\mathrm{L} .) \\
\text { DC. }\end{array}$} & A & 8.06 & $50.04 \pm 5.08 * * *$ & $106.98 \pm 6.35^{* * *}$ \\
\hline & B & 3.55 & $96.06 \pm 0.91 * * *$ & $112.19 \pm 6.16^{* * *}$ \\
\hline & $\mathrm{C}$ & 7.42 & $77.45 \pm 6.44 * * *$ & $84.22 \pm 4.09 * * *$ \\
\hline & $\mathrm{D}$ & 54.84 & $32.52 \pm 5.43 * * *$ & $45.18 \pm 6.47 * * *$ \\
\hline \multirow[t]{4}{*}{ L. forsteri (Sm.) DC. } & A & 10.54 & $71.53 \pm 7.75^{* * *}$ & $71.88 \pm 7.07 * * *$ \\
\hline & B & 6.67 & $93.14 \pm 6.14 * * *$ & $113.51 \pm 1.07 * * *$ \\
\hline & $\mathrm{C}$ & 46.67 & $35.24 \pm 1.43 * * *$ & $37.95 \pm 6.88^{* *}$ \\
\hline & $\mathrm{D}$ & 22.67 & $32.80 \pm 3.40 * * *$ & $54.52 \pm 0.99 * * *$ \\
\hline \multirow{4}{*}{$\begin{array}{l}\text { L. luzuloides (Lam.) } \\
\text { Dandy \& Wilmott }\end{array}$} & A & 23.44 & $70.65 \pm 6.65^{* * *}$ & $92.50 \pm 3.58 * * *$ \\
\hline & B & 4.69 & $99.39 \pm 0.37 * * *$ & $114.22 \pm 3.13^{* * *}$ \\
\hline & $\mathrm{C}$ & 49.89 & $62.84 \pm 3.50 * * *$ & $68.39 \pm 5.74 * * *$ \\
\hline & $\mathrm{D}$ & 11.18 & $68.80 \pm 5.92 * * *$ & $77.71 \pm 4.99 * * *$ \\
\hline \multirow{4}{*}{$\begin{array}{l}\text { L. sudetica (Willd.) } \\
\text { Schult. }\end{array}$} & A & 17.86 & $72.85 \pm 6.35^{* * *}$ & $76.08 \pm 5.45^{* * *}$ \\
\hline & B & 7.14 & $109.25 \pm 6.01 * * *$ & $115.21 \pm 4.14^{* * *}$ \\
\hline & $\mathrm{C}$ & 17.86 & $77.95 \pm 0.22 * * *$ & $91.41 \pm 1.84 * * *$ \\
\hline & $\mathrm{D}$ & 47.62 & $37.92 \pm 5.39 * *$ & $8.59 \pm 3.19$ \\
\hline \multirow{4}{*}{$\begin{array}{l}\text { L. sylvatica (Huds.) } \\
\text { Gaudin (aerial part) }\end{array}$} & A & 8.57 & $85.27 \pm 4.20^{* * *}$ & $89.10 \pm 6.41 * * *$ \\
\hline & B & 5.71 & $96.09 \pm 1.92 * * *$ & $111.90 \pm 2.99 * * *$ \\
\hline & $\mathrm{C}$ & 18.10 & $73.32 \pm 2.91 * * *$ & $54.82 \pm 4.11 * * *$ \\
\hline & $\mathrm{D}$ & 43.81 & $26.90 \pm 7.01^{* *}$ & $48.83 \pm 6.51^{* *}$ \\
\hline \multirow[t]{4}{*}{ L. sylvatica (root part) } & A & 7.96 & $89.18 \pm 6.58 * * *$ & $107.88 \pm 3.96 * * *$ \\
\hline & B & 4.69 & $95.28 \pm 2.48 * * *$ & $104.23 \pm 5.67 * * *$ \\
\hline & $\mathrm{C}$ & 46.12 & $53.62 \pm 7.13^{* * *}$ & $54.13 \pm 3.03 * * *$ \\
\hline & $\mathrm{D}$ & 12.65 & $41.60 \pm 6.19 * * *$ & $43.02 \pm 2.96^{* * *}$ \\
\hline
\end{tabular}

$\mathrm{A}=n$-hexane fraction, $\mathrm{B}=\mathrm{CH}_{2} \mathrm{Cl}_{2}$ fraction, $\mathrm{C}=$ EtOAc fraction, $\mathrm{D}=$ remaining $\mathrm{H}_{2} \mathrm{O}$ fraction.

Results are presented as mean \pm S.E.M. $(n=3-5) . \quad * * P<0.01, \quad * * * P<0.001$ compared with the control value (DMSO). ial allowed the separation of L. sylvatica into aerial and root parts, therefore methanol extracts were prepared from selected plant organs in case of L. sylvatica. The crude extracts were concentrated and suspended in $50 \% \mathrm{MeOH}$, and then solvent-solvent partitions were made with $n$-hexane (A), $\mathrm{CH}_{2} \mathrm{Cl}_{2}$ (B), and EtOAc (C). The remaining $\mathrm{H}_{2} \mathrm{O}$ fractions were signed as $\mathrm{D}$ (altogether 24 extracts). The apolar, $n$-hexane-soluble fractions of $L$. forsteri, L. luzuloides, $L$. sudetica and L. sylvatica showed $>70 \%$ inhibition at the tested concentration $(10 \mu \mathrm{g} / \mathrm{mL})$ in both anti-inflammatory assays. The fraction A of $L$. campestris exerted the most selective elastase release inhibition. Among the fractions with different polarities, fractions B (containing $\mathrm{CH}_{2} \mathrm{Cl}_{2}$-soluble lipophilic constituents) had the most remarkable activities ( $>93 \%$ inhibition) at concentration of $10 \mu \mathrm{g} / \mathrm{mL}$. All of the $\mathrm{CH}_{2} \mathrm{Cl}_{2}$-soluble fractions displayed significant activities on the inhibition of elastase release, and proved to be slightly less active on superoxide generation. The EtOAc-soluble fractions of $L$. campestris, $L$. luzuloides, L. sudetica, L. sylvatica (aerial part) possessed noteworthy $(>65 \%)$ inhibitory activities at concentration of $10 \mu \mathrm{g} / \mathrm{mL}$. The remaining $\mathrm{H}_{2} \mathrm{O}$ fraction of $L$. luzuloides also showed notable anti-inflammatory activities ( $>65 \%$ ) in both methods. On the basis of these preliminary results, L. luzuloides has been chosen for further investigation.

Dried whole plant material of $L$. luzuloides ( $480 \mathrm{~g}$ ) was powdered and extracted with methanol at room temperature. After concentration, the extract was dissolved in 50\% aqueous $\mathrm{MeOH}$, and solvent-solvent partition was performed with $n$-hexane, $\mathrm{CH}_{2} \mathrm{Cl}_{2}$, and EtOAc. The $\mathrm{CH}_{2} \mathrm{Cl}_{2}$ fraction was separated and purified with the combination of different chromatographic methods (CC, VLC, Sephadex LH-20 gel chromatography, prep TLC) to afford 6 compounds (1-6, Fig. 1).

The structure determination was carried out by extensive spectroscopic analysis, using one- and two-dimensional NMR $\left({ }^{1} \mathrm{H}-{ }^{1} \mathrm{H}\right.$ COSY, HSQC, HMBC) spectroscopy, HRESIMS and HPLC-ECD experiments and comparison of the spectral data with literature data.

Compound 1 was obtained as an amorphous solid with $[\alpha]_{\mathrm{D}}{ }^{26} 0(c$ $0.1, \mathrm{MeOH})$. Its HRESIMS provided the molecular formula $\mathrm{C}_{18} \mathrm{H}_{16} \mathrm{O}_{3}$ through the presence of a peak at $\mathrm{m} / z 281.1175[\mathrm{M}+\mathrm{H}]^{+}$(calcd for $\mathrm{C}_{18} \mathrm{H}_{17} \mathrm{O}_{3}, 281.1172$ ). The ${ }^{\mathrm{I}} \mathrm{H}$ NMR spectrum (Table 2) displayed signals of two pairs of ortho-coupled aromatic protons $\left(\delta_{\mathrm{H}} 6.25 \mathrm{~d} / 8.35\right.$ $\mathrm{d}$ and $\left.\delta_{\mathrm{H}} 8.12 \mathrm{~d} / 7.63 \mathrm{~d}\right)$, and one aromatic proton as a singlet $\left(\delta_{\mathrm{H}}\right.$ 7.52), two methyl singlets at $\delta_{\mathrm{H}} 1.53$ and $\delta_{\mathrm{H}} 2.35$, and a vinylic system at $\delta_{\mathrm{H}} 5.81,5.35$ and $7.05(\mathrm{C}-14, \mathrm{C}-13)$. In the JMOD spectrum, the presence of 18 carbon signals was detected (Table 2). In the ${ }^{1} \mathrm{H}$ NMR spectrum the presence of ortho-coupled aromatic protons at $\delta_{\mathrm{H}}$ $8.12 \mathrm{~d}$ and $7.63 \mathrm{~d}$ could be assigned to the H-9 and H-10 protons of a phenanthrene derivative. In the ${ }^{1} \mathrm{H},{ }^{1} \mathrm{H}-\mathrm{COSY}$ spectrum four correlations were observed between $\delta_{\mathrm{H}} 8.12 \mathrm{~d}$ and $7.63 \mathrm{~d}(\mathrm{H}-9 / \mathrm{H}-10)$, between $\delta_{\mathrm{H}} 6.25 \mathrm{~d}$ and $8.35 \mathrm{~d}(\mathrm{H}-3 / \mathrm{H}-4)$, between $\delta_{\mathrm{H}} 7.05 \mathrm{dd}$ and $5.81 \mathrm{~d}$ $(\mathrm{H}-13 / \mathrm{H}-14 \mathrm{a})$, and between $\delta_{\mathrm{H}} 7.05 \mathrm{dd}$ and $5.35 \mathrm{~d}(\mathrm{H}-13 / \mathrm{H}-14 \mathrm{~b})$. The two ortho-coupled doublets at $\delta_{\mathrm{H}} 6.25$ and 8.35 were assigned to the $\mathrm{H}-3$ and H-4 protons. According to the ${ }^{13} \mathrm{C}$ NMR signals at $\delta_{\mathrm{C}} 207.1$ one carbonyl group was identified, which was placed to $\mathrm{C}-2$ as confirmed by $\mathrm{HMBC}$ correlations of the $11-\mathrm{CH}_{3}\left(\delta_{\mathrm{H}} 1.53\right)$ and $\mathrm{H}-4\left(\delta_{\mathrm{H}}\right.$ 8.35 d) with $\mathrm{C}-2\left(\delta_{\mathrm{C}} 207.1\right)$ (Table 2 , Fig. 2$)$. The location of one of the methyl groups $\left(\delta_{\mathrm{H}} 1.53 \mathrm{~s}\right)$ was confirmed at $\mathrm{C}-1$ on the basis of its $\mathrm{HMBC}$ correlation with the quaternary carbons $\delta_{\mathrm{C}} 146.6(\mathrm{C}-1 \mathrm{a})$, $78.1(\mathrm{C}-1)$ and 207.1 (C-2). The linkage of hydroxy groups to $\mathrm{C}-1$ and C-6 was confirmed by the chemical shifts of the quaternary carbons at $\delta_{\mathrm{C}-1} 78.1$ and $\delta_{\mathrm{C}-6} 157.0$, respectively. In the $\mathrm{HMBC}$ spectrum another methyl group was assigned at $\mathrm{C}-7$ by the correlation of $\mathrm{H}-12 / \mathrm{C}-7$. The vinyl substitution at $\mathrm{C}-8$ was indicated by the HMBC cross-peaks between $\mathrm{H}-14 \mathrm{a} / \mathrm{C}-8$ and $\mathrm{H}-14 \mathrm{~b} / \mathrm{C}-8$. 


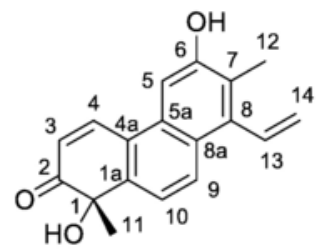

(S)-1 (25\% ee) (luzulin A)<smiles>[R]c1c([R])c([R])c2c(c1[R])CCc1c-2ccc(O)c1C</smiles>

$\begin{array}{llll}\mathrm{R}_{1} & \mathrm{R}_{2} & \mathrm{R}_{3} & \mathrm{R}_{4}\end{array}$
$2 \begin{array}{llll}\mathrm{CH} & =\mathrm{CH}_{2} & \mathrm{CH}_{3} & \mathrm{OH}\end{array}$

$3 \mathrm{H} \quad \mathrm{OH} \quad \mathrm{CH}_{3} \quad \mathrm{CH}=\mathrm{CH}_{2}$<smiles>[R]c1c([R])c([R])c2c(ccc3c(C)c(O)ccc32)c1[R]</smiles>

$\mathrm{R}_{1}$

$\mathrm{R}_{2}$

$\mathrm{R}_{3}$

$\mathrm{R}_{4}$

$4 \mathrm{H}$

$\mathrm{OH}$

$\mathrm{CH}_{3}$

$\mathrm{CH}=\mathrm{CH}_{2}$<smiles>[R]c1cc(-c2cc(=O)c3c(O)cc(O)cc3o2)ccc1O</smiles>

$\mathrm{R}$

$5 \mathrm{H}$

$6 \mathrm{OH}$<smiles>C=CC1=C(C)C(=O)C=C2c3ccc(O)c(C)c3CCC21O</smiles>

7

Fig. 1. Structures of compounds 1-7.

The NOESY correlations further confirmed the structure of compound 1. Overhauser effects were detected between $\mathrm{H}-3 / \mathrm{H}-4, \mathrm{H}-4 /$ H-5, H-9/H-10, H-9/H-13, H-9/H-14b, H-13/ $\mathrm{CH}_{3}-12, \mathrm{H}-14 \mathrm{~b} / \mathrm{CH}_{3}-12$. All of the above evidence confirmed the planar structure of 1 named as luzulin A (Fig. 1).

Luzulin A (1) is a chiral natural product but it had a very weak ECD spectrum in acetonitrile and zero specific rotation, which suggested that it had low enantiomeric excess. Thus chiral HPLC analysis of 1 was carried out, which resulted in the separation of the two enantiomers on a Chiralpak IA column and determined the enantiomeric excess as $25 \%$. The quaternary stereogenic center does not enable inversion of the absolute configuration during the isolation and hence the low enantiomeric excess can be attributed to the low enantioselectivity of the biosynthetic step, which has been observed for other natural phenanthrenes as well [38].

In order to elucidate the absolute configuration of the enantiomers and identify the major enantiomer, HPLC-ECD spectra of the separated enantiomers were recorded and the solution TDDFT-ECD protocol was applied on the arbitrarily chosen $(R)$ enantiomer (Fig. 3) [36]. The initial Merck Molecular Force Field (MMFF) conformational search resulted in 5 conformers in a $21 \mathrm{~kJ} / \mathrm{mol}$ energy window, which were reoptimized at various DFT levels [B3LYP/6-31G(d) in vacuo, B97D/TZVP $\mathrm{PCM} / \mathrm{CHCl}_{3}$ and CAM-B3LYP/TZVP PCM/ $\mathrm{CHCl}_{3}$ ] and ECD spectra were computed with B3LYP, BH\&HLYP, CAM-B3LYP and PBE0 functionals and TZVP basis set. The computed conformers differed in the orientation of the OH- 6 proton and the C-8 vinyl group, the latter of which influenced the ECD spectra as well. The OH-1 group adopted equatorial position in all the computed conformers (Fig. 4). All the applied combinations for all conformers reproduced the first two transitions at ca. 422 and $375 \mathrm{~nm}$ and Boltzmann-weighted spectra acquired at all applied levels resembled also the high-energy transitions at ca. 227 and $206 \mathrm{~nm}$ allowing the elucidation of the absolute configuration as $(R)$ for the first-eluting enantiomer (minor component) and $(S)$ for the second-eluting enantiomer (major component). Interestingly, the $312 \mathrm{~nm}$ Cotton effect (CE) could not be reproduced by any applied combination of theoretical levels, which can be attributed to difficulties in estimating the proper orientation of the conjugating quite freely rotating vinyl chromophore and the overlapping transitions of this region [37].

Besides the new compound, luzulin A (1), two dihydrophenanthrenes [juncusol (2) and juncuenin B (3)], one phenanthrene [dehydrojuncuenin B (4)] and two flavonoids [apigenin (5) and luteolin 
Table 2

NMR spectroscopic data for luzulin A (1) (500 MHz, $\left.\mathrm{CD}_{3} \mathrm{OD}\right)$

\begin{tabular}{|c|c|c|c|}
\hline Position & 1 & & \\
\hline & $\delta_{\mathrm{H}}(J$ in $\mathrm{Hz})$ & $\delta_{\mathrm{C}}$, type & $\mathrm{HMBC}(\mathrm{H} \rightarrow \mathrm{C})$ \\
\hline 1 & & $78.1, \mathrm{C}$ & \\
\hline 1a & & 146.6, C & \\
\hline 2 & & 207.1, C & \\
\hline 3 & $6.25, \mathrm{~d}(10.2)$ & $123.1, \mathrm{CH}$ & $1,4 \mathrm{a}$ \\
\hline 4 & $8.35, \mathrm{~d}(10.1)$ & $141.9, \mathrm{CH}$ & $1 \mathrm{a}, 2$ \\
\hline $4 a$ & & $122.6, \mathrm{C}$ & \\
\hline 5 & $7.52, \mathrm{~s}$ & $103.3, \mathrm{CH}$ & $4 a, 6,8 a$ \\
\hline $5 \mathrm{a}$ & & $132.2, \mathrm{C}$ & \\
\hline 6 & & 157.0, C & \\
\hline 7 & & $126.3, \mathrm{C}$ & \\
\hline 8 & & $138.3, \mathrm{C}$ & \\
\hline $8 \mathrm{a}$ & & $127.7, \mathrm{C}$ & \\
\hline 9 & $8.12, \mathrm{~d}(8.5)$ & $129.8, \mathrm{CH}$ & $1 \mathrm{a}, 5 \mathrm{a}$ \\
\hline 10 & $7.63, \mathrm{~d}(8.7)$ & $121.0, \mathrm{CH}$ & $4 a, 8 a$ \\
\hline 11 & $1.53, \mathrm{~s}$ & $32.1, \mathrm{CH}_{3}$ & $1,1 \mathrm{a}, 2$ \\
\hline 12 & $2.35, \mathrm{~s}$ & $13.4, \mathrm{CH}_{3}$ & $6,7,8$ \\
\hline 13 & 7.05, dd $(17.9,11.5)$ & $135.7, \mathrm{CH}$ & \\
\hline $14 \mathrm{a}$ & $5.81, \mathrm{~d}(11.5)$ & $122.2, \mathrm{CH}_{2}$ & 8 \\
\hline $14 \mathrm{~b}$ & $5.35, \mathrm{~d}(18.0)$ & & 8 \\
\hline
\end{tabular}

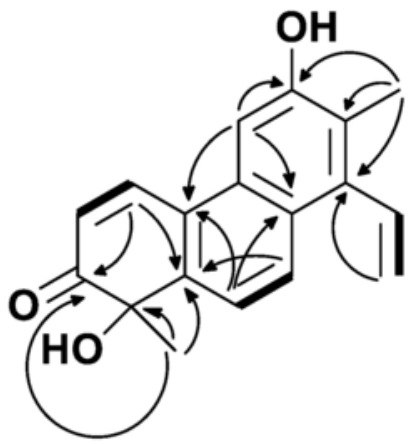

Fig. 2. Diagnostic COSY (-) and HMBC correlations $(\rightarrow)$ for $\mathbf{1}$.

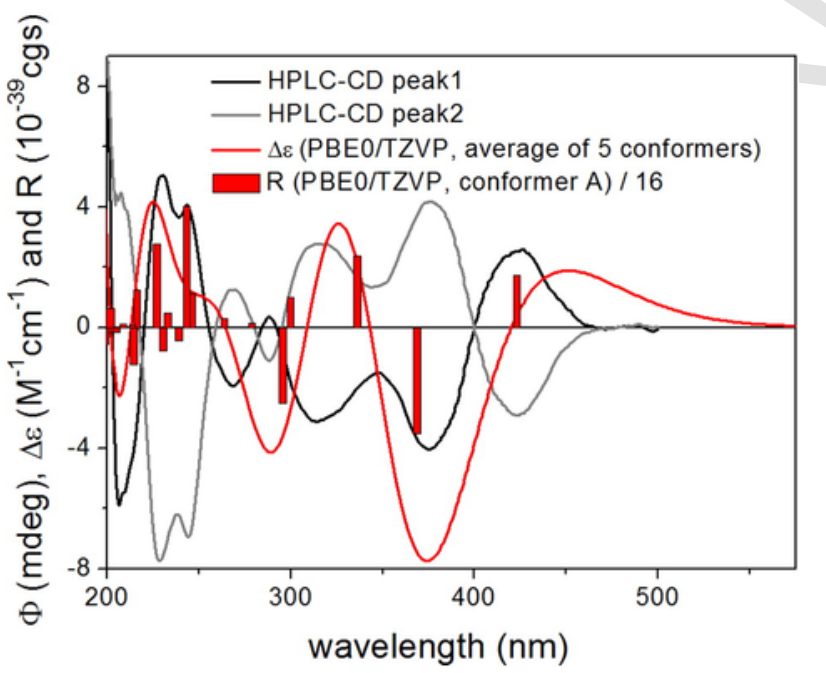

Fig. 3. Experimental HPLC-ECD spectra of $\mathbf{1}$ (black: first eluting enantiomer; grey: second eluting enantiomer) compared with the Boltzmann-weighted PBE0/TZVP $\left(\mathrm{PCM} / \mathrm{CHCl}_{3}\right)$ ECD spectrum of $(R)-1$ computed for the B97D/TZVP PCM/CHCl 3 conformers. Bars represent the rotational strength of the lowest-energy conformer.
(6)] were also isolated from L. luzuloides. Their structures were determined by analyses of MS, 1D and 2D NMR data, and by comparison with literature data [38-40].

All compounds were isolated for the first time from L. luzuloides. The methyl group at C-1, a hydroxyl group at C-2 and vinyl, methyl and hydroxyl substitution on ring $B$ are characteristic features of the isolated phenanthrenes. In compound $\mathbf{1}$, a carbonyl group can also be found in the molecule. The absolute configuration of luzulin A (1) was determined by HPLC-ECD measurements and TDDFT-ECD calculations.

So far $>90$ novel phenanthrenes have been reported from 6 Juncus species ( $J$. acutus, J. effusus, J. inflexus, J. roemerianus, J. setchuensis and $J$. subulatus) [5-7,38]. The first example of nitrogen-free alkylated phenanthrenes was juncusol (2) isolated from $J$. roemerianus [41]. Until now phenanthrenes have not been isolated from the genus Luzula. This was the first time when extensive phytochemical and pharmacological investigations were performed with the genus Luzula and with L. luzuloides. Our results allowed the identification of four phenanthrenes $(\mathbf{1}-\mathbf{4})$ substituted with vinyl, hydroxyl, methyl and methoxy groups, one of them (1) is new natural product. The other phenanthrenes (2-4) were isolated previously only from other Juncaceae species. All of the compounds were isolated for the first time from L. luzuloides.

In the course of our previous investigations considerable amount of juncuenin B (3) (850 mg) and its unsaturated form, dehydrojuncuenin B (4) have been isolated from $J$. inflexus [38]. Luzulin A (1) from $L$. luzuloides and juncuenin D (7) from J. inflexus have obvious structure similarity with the abovementioned two phenanthrenes [juncuenin B (3) and dehydrojuncuenin B (4)], suggesting that both phenanthrenequinones are possibly derived from the oxidation of juncuenin B (3). In the case of luzulin A (1), ring A is oxidized, and in the case of juncuenin $\mathrm{D}$ (7) ring $\mathrm{C}$ has changed. In order to confirm their possible biosynthetic connection, juncuenin B (3) was subjected to an oxidative reaction by the use of hypervalent iodine reagent (PIFA). $50 \mathrm{mg}$ juncuenin $\mathrm{B}$ (3) was dissolved in $\mathrm{CH}_{3} \mathrm{CN}-\mathrm{H}_{2} \mathrm{O}$ (9:1, $1 \mathrm{mg} / \mathrm{mL}$ ), and a reaction with 2 eq. of PIFA was performed at room temperature for $30 \mathrm{~min}$ (Scheme 1). After purification by NP-VLC, Sephadex LH-20 gel filtration and preparative TLC, three major compounds were isolated from the mixture. The compounds were identified as juncuenin D $(7,22 \%)$, dehydrojuncuenin $\mathrm{B}(4,18 \%)$ and luzulin $\mathrm{A}(\mathbf{1}, 16 \%)$ by comparison of their ${ }^{1} \mathrm{H}$ NMR spectrum with literature data [5]. These findings confirm that luzulin A (1) and juncuenin D (7) can form by oxidation of juncuenin B (3), and most probably similar process may be performing during their biosynthesis. Although, several phenanthrenes and flavonoids have been reported to exhibit remarkable anti-inflammatory activity, there were no previous data for the anti-inflammatory effects of metabolites from the genus Luzula. In the performed assay, effects against superoxide anion production and elastase release by human neutrophils in response to $\mathrm{fMLP} / \mathrm{CB}$ were measured according to previously published methods $[26,27]$. Among the isolated compounds, noteworthy anti-inflammatory activities were measured for juncusol (2), juncuenin B (3), dehydrojuncuenin B (4), apigenin (5) and luteolin (6) (Table 3). Although great deals of phenanthrenes were assayed for their anti-inflammatory properties, this was the first time when the anti-inflammatory activity of the isolated phenanthrenes $(\mathbf{1}-\mathbf{4}, \mathbf{7})$ was evaluated $[5,6]$.

In the superoxide anion generation assay, significant inhibitory activities were recorded for juncusol $(2)\left(\mathrm{IC}_{50}=3.11 \mu \mathrm{M}\right)$, juncuenin $\mathrm{B}$ (3) $\left(\mathrm{IC}_{50}=4.92 \mu \mathrm{M}\right)$, dehydrojuncuenin $\mathrm{B}(4)\left(\mathrm{IC}_{50}=3.17 \mu \mathrm{M}\right)$, apigenin (5) $\left(\mathrm{IC}_{50}=6.12 \mu \mathrm{M}\right)$, and luteolin (6) $\left(\mathrm{IC}_{50}=4.73 \mu \mathrm{M}\right)$. Furthermore, juncuenin B (3) and luteolin (6) inhibited effectively the 


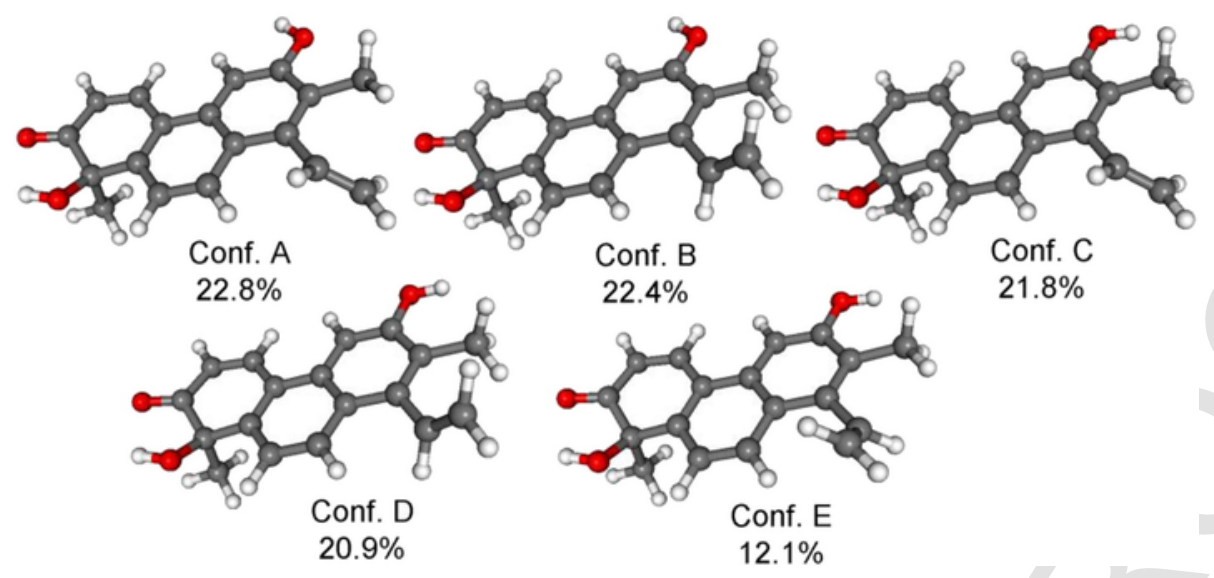

Fig. 4. Structures and populations of the B97D/TZVP PCM/CHCl 3 conformers of $(R)-\mathbf{1}$.<smiles>C=Cc1c(C)c(O)cc2c3c(ccc12)C(C)(O)C(=O)C=C3</smiles>

Scheme 1. Oxidation of juncuenin B (3).

elastase release with $\mathrm{IC}_{50} \mathrm{~S} 5.47 \mu \mathrm{M}$ and $6.91 \mu \mathrm{M}$, respectively, comparable to that of LY294002 $\left(\mathrm{IC}_{50}=4.79 \mu \mathrm{M}\right)$. These results suggest that compounds 2-6 display promising anti-inflammatory activity, juncusol (2), dehydrojuncuenin B (4) and apigenin (5) were considered to be active only in case of inhibition of superoxide generation, while luzulin A (1) and juncuenin D (7) were proved to be inactive in both assays. With its unsaturation at ring B, juncuenin B (3) lost its effect on the elastase release, but dehydrojuncuenin B (4) inhibited the superoxide generation more effectively than juncuenin B (3). The two phenanthrenequinones, luzulin A (1) and juncuenin D (7), presumably derived from juncuenin B (3) showed significantly lower anti-inflammatory activities compared to their possible biosynthetic precursor.

In conclusion, phenanthrenes are the most characteristic compounds of Juncaceae species. Although phenanthrenes have been identified from taxonomically distant families [6], vinyl substituted derivatives can be considered as chemotaxonomic markers for plants belonging to Juncaceae family, since these specifically substituted phenanthrenes were only reported from Juncus species, and this was the first time when they were isolated from the genus Luzula. The chemical characterization of $L$. luzuloides, and the presence of vinylated phenanthrenes in the plant further confirm the close botanical relationship between the genera Luzula and Juncus.

This was the first time when the anti-inflammatory activity of species belonging to the genus Luzula was evaluated. Along with the extracts prepared from different species of the genus, several isolated compounds showed promising anti-inflammatory activities. The present study highlights that phytochemical and pharmacological studies of the previously uninvestigated genus Luzula are very promising. 
Table 3

Inhibitory effects of compounds $\mathbf{1 - 7}$ on superoxide anion generation and elastase release by human neutrophils in response to $\mathrm{ALP} / \mathrm{CB}$.

\begin{tabular}{lllll}
\hline Compound & \multicolumn{2}{l}{ Superoxide anion } & \multicolumn{2}{l}{ Elastase release } \\
\hline & $\mathrm{IC}_{50}(\mu \mathrm{M})$ & Inhibition $(\%)$ & $\mathrm{IC}_{50}(\mu \mathrm{M})$ & Inhibition $(\%)$ \\
\hline $\mathbf{1}$ & $>10$ & $12.26 \pm 3.76^{*}$ & $>10$ & $40.5 \pm 5.57^{* *}$ \\
$\mathbf{2}$ & $3.11 \pm 0.25$ & $93.07 \pm 0.48^{* * *}$ & $>10$ & $2.05 \pm 2.07$ \\
$\mathbf{3}$ & $4.92 \pm 0.27$ & $81.54 \pm 3.5^{* * *}$ & $5.47 \pm 1.11$ & $80.57 \pm 4.15^{* * *}$ \\
$\mathbf{4}$ & $3.17 \pm 1.19$ & $82.90 \pm 7.65^{* * *}$ & $>10$ & $25.58 \pm 2.83^{* *}$ \\
$\mathbf{5}$ & $6.12 \pm 0.72$ & $73.92 \pm 4.11^{* * *}$ & $>10$ & $46.14 \pm 6.03^{* *}$ \\
$\mathbf{6}$ & $4.73 \pm 0.49$ & $79.77 \pm 4.37^{* * *}$ & $6.91 \pm 2.25$ & $54.16 \pm 4.66^{* * *}$ \\
$\mathbf{7}$ & $>10$ & $43.29 \pm 5.77^{* * *}$ & $>10$ & $32.75 \pm 6.98^{* *}$ \\
$\mathrm{LY} 294002$ & $1.29 \pm 0.05$ & - & $4.97 \pm 0.80$ & - \\
\hline
\end{tabular}

Percentage of inhibition (inhibition \%) at $10 \mu \mathrm{M}$ concentration. Results are presented as mean \pm S.E.M. $(n=3-5)$. ${ }^{*} P<0.05$, ${ }^{*} * P<0.01, * * * P<0.001$ compared with the control value. LY294002, a PI3K inhibitor, was used as positive control.

\section{Conflict of interest}

The authors declare no competing financial interest.

\section{Acknowledgements}

Financial support from the Hungarian Scientific Research Fund (OTKA K109846) is gratefully acknowledged. A.V. acknowledges the award of a János Bolyai scholarship of the Hungarian Academy of Sciences. T.K. thanks the Hungarian National Research Foundation (OTKA K105871) for financial support and the National Information Infrastructure Development Institute (NIIFI 10038) for CPU time. T.L.H. thanks the Chang Gung Memorial Hospital (CMRPD1B0281 3, CMRPF1D0442 3, CMRPF 1F0011 3, CMRPF1F0061 3 and BMRP450) for financial support. The authors would like to thank to Attila Csorba (Department of Pharmacognosy, University of Szeged) for the HRMS measurements.

\section{Appendix A. Supplementary data}

1D and 2D NMR and ECD spectra of compound 1 are available in the Supplementary data. Supplementary data associated with this article can be found in the online version, at 10.1016/j.fitote.2016.12.004.

\section{References}

[1] The plant list, in: http://www.theplantlist.org/browse/A/Juncaceae/ (accessed 16.08.15).

[2] L. Drábková, J. Kirschner, O. Seberg, G. Petersen, C. Vlcek, Phylogeny of the Juncaceae based on rbc L sequences, with special emphasis on Luzula DC. and Juncus L., Plant Syst. Evol. 240 (2003) 133-147.

[3] Y.G. Wang, Y.L. Wang, H.F. Zhai, Y.J. Liao, B. Zhang, J.M. Huang, Phenanthrenes from Juncus effusus with anxiolytic and sedative activities, Nat. Prod. Res. 26 (2012) 1234-1239.

[4] K. Shima, M. Toyota, Y. Asakawa, Phenanthrene derivatives from the medullae of Juncus effusus, Phytochemistry 30 (1991) 3149-3151.

[5] X.Y. Wang, C.Q. Ke, C.P. Tang, D. Yuan, Y. Ye, 9,10-dihydrophenanthrenes and phenanthrenes from Juncus setchuensis, J. Nat. Prod. 72 (2009) 1209-1212.

[6] A. Kovács, A. Vasas, J. Hohmann, Natural phenanthrenes and their biological activity, Phytochemistry 69 (2008) 1084-1110.

[7] A.F. Abdel-Razik, A.-S.I. Elshamy, M.I. Nassar, S.M. El-Kousy, H. Hamdy, Chemical constituents and hepatoprotective activity of Juncus subulatus, Rev. Latinoam. Quim. 37 (2009) 70-84.

[8] X.H. Su, Z.P. Yuan, C.Y. Li, Y.J. Zhong, H.J. Du, Y.Y. Wen, Y.F. Li, B. Liang, Phenanthrenes from Juncus effusus, Planta Med. 79 (2013) 1447-1452.

[9] K. Ishiuchi, Y. Kosuge, H. Hamagami, M. Ozaki, K. Ishige, Y. Ito, S. Kitanaka, Chemical constituents isolated from Juncus effusus induce cytotoxicity in HT22 cells, J. Nat. Med. 69 (2015) 421-426.
[10] A. Stabursvik, Luteolin-7-glucoside as a characteristic component of the plant genera Juncus and Luzula (family Juncaceae), Acta Chem. Scand. 22 (1968) 2371-2373.

[11] C.A. Williams, J.B. Harborne, Luteolin and daphnetin derivatives in the Juncaceae and their systematic significance, Biochem. Syst. Ecol. 3 (1975) $181-190$.

[12] M. Della Greca, A. Fiorentino, M. Isidori, L. Previtera, F. Temussi, A. Zarrelli, Benzocoumarins from the rhizomes of Juncus acutus, Tetrahedron 59 (2003) $4821-4825$.

[13] G.Z. Yang, H.X. Li, F.J. Song, Y. Chen, Diterpenoid and phenolic compounds from Juncus effusus L., Helv. Chim. Acta 90 (2007) 1289-1295.

[14] A. Stabursvik, The carotenoids of two Juncus spp. (family Juncaceae) and one Scirpus sp. (family Cyperaceae), Acta Chem. Scand. 22 (1968) 2056-2057.

[15] M. Della Greca, A. Fiorentino, P. Monaco, L. Previtera, Cycloartane triterpenes from Juncus effusus, Phytochemistry 35 (1994) 1017-1022.

[16] S. Park, S. Yang, D. Ahn, J.H. Yang, D.K. Kim, Antioxidative phenolic compounds from the whole plant of Juncus diastrophanthus, J. Korean Soc. Appl. Biol. Chem. 54 (2011) 685-692.

[17] W. Ma, F. Liu, Y.Y. Ding, Y. Zhang, N. Li, Four new phenanthrenoid dimers from Juncus effusus L. with cytotoxic and anti-inflammatory activities, Fitoterapia 105 (2015) 83-88

[18] W. Ma, Y. Zhang, Y.-Y. Ding, F. Liu, N. Li, Cytotoxic and anti-inflammatory activities of phenanthrenes from the medullae of Juncus effusus L., Arch. Pharm. Res. 39 (2015) 154-160.

[19] F.A.A. Behery, Z.E.M. Naeem, G.T. Maatooq, M.M.A. Amer, Z.H. Wen, J.-H. Sheu, A.F. Ahmed, Phenanthrenoids from Juncus acutus L., new natural lipopolysaccharide-inducible nitric oxide synthase inhibitors, Chem. Pharm. Bull. 55 (2007) 1264-1266.

[20] F.A.A. Behery, Z.E.M. Naeem, G.T. Maatooq, M.M.A. Amer, A.F. Ahmed, A novel antioxidant phenanthrenoid dimer from Juncus acutus L., Nat. Prod. Res. 27 (2013) 155-163.

[21] O. Benavente-García, J. Castillo, Update on uses and properties of citrus flavonoids: new findings in anticancer, cardiovascular, and anti-inflammatory activity, J. Agric. Food Chem. 56 (2008) 6185-6205.

[22] M. Serafini, I. Peluso, A. Raguzzini, 3rd international immunonutrition workshop. Session 1: antioxidants and the immune system, flavonoids as anti-inflammatory agents, Proc. Nutr. Soc. 69 (2010) 273-278.

[23] H.K. Kim, B.S. Cheon, Y.H. Kim, S.Y. Kim, H.P. Kim, Effects of naturally occurring flavonoids on nitric oxide production in the macrophage cell line RAW 264.7 and their structure-activity relationships, Biochem. Pharmacol. 58 (1999) $759-765$.

[24] Y.C. Liang, Y.T. Huang, S.H. Tsai, S.Y. Lin-Shiau, C.F. Chen, J.K. Lin, Suppression of inducible cyclooxygenase and inducible nitric oxide synthase by apigenin and related flavonoids in mouse macrophages, Carcinogenesis 20 (1999) 1945-1952.

[25] M. Funakoshi-Tago, K. Nakamura, K. Tago, T. Mashino, T. Kasahara, Anti-inflammatory activity of structurally related flavonoids, apigenin, luteolin and fisetin, Int. Immunopharmacol. 11 (2011) 1150-1159.

[26] T.L. Hwang, G.L. Li, Y.H. Lan, Y.C. Chia, P.W. Hsieh, Y.H. Wu, Y.C. Wu, Potent inhibition of superoxide anion production in activated human neutrophils by isopedicin, a bioactive component of the Chinese medicinal herb Fissistigma oldhamii, Free Radic. Biol. Med. 46 (2009) 520-528.

[27] S.C. Yang, P.J. Chung, C.M. Ho, C.Y. Kuo, M.F. Hung, Y.T. Huang, W.Y. Chang, Y.W. Chang, K.H. Chan, T.L. Hwang, Propofol inhibits superoxide production, elastase release, and chemotaxis in formyl peptide-activated human neutrophils by blocking formyl peptide receptor 1, J. Immunol. 190 (2013) 6511-6519.

[28] MacroModel, L.L.C. Schrödinger, in: http://www.schrodinger.com/ MacroModel, 2012 (accessed 16.08.15)

[29] S. Grimme, Semiempirical GGA-type density functional constructed with a long-range dispersion correction, J. Comput. Chem. 27 (2006) 1787-1799.

[30] P. Sun, D.-X. Xu, A. Mándi, T. Kurtán, T.-J. Li, B. Schulz, W. Zhang, Structure, absolute configuration, and conformational study of 12 -membered macrolides from the fungus Dendrodochium sp. associated with the sea cucumber Holothuria nobilis Selenka, J. Org. Chem. 78 (2013) 7030-7047.

[31] T. Yanai, D. Tew, N. Handy, A new hybrid exchange-correlation functional using the coulomb-attenuating method (CAM-B3LYP), Chem. Phys. Lett. 393 (2004) 51-57.

[32] G. Pescitelli, L. Di Bari, N. Berova, Conformational aspects in the studies of organic compounds by electronic circular dichroism, Chem. Soc. Rev. 40 (2011) $4603-4625$.

[33] M.J. Frisch, G.W. Trucks, H.B. Schlegel, G.E. Scuseria, M.A. Robb, J.R. Cheeseman, G. Scalmani, V. Barone, B. Mennucci, G.A. Petersson, H. Nakatsuji, M. Caricato, X. Li, H.P. Hratchian, A.F. Izmaylov, J. Bloino, G. Zheng, J.L. Sonnenberg, M. Hada, M. Ehara, K. Toyota, R. Fukuda, J. Hasegawa, M. Ishida, T. Nakajima, Y. Honda, O. Kitao, H. Nakai, T. Vreven, J.A. Montgomery Jr., J.E. Peralta, F. Ogliaro, M. Bearpark, J.J. Heyd, E. Brothers, K.N. Kudin, V.N. Staroverov, R. Kobayashi, J. Normand, K. Raghavachari, A. Rendell, J.C. Burant, S.S. Iyengar, J. Tomasi, M. Cossi, N. Rega, J.M. Millam, M. Klene, J.E. Knox, J.B. Cross, V. Bakken, C. Adamo, J. Jaramillo, R. Gomperts, 
R.E. Stratmann, O. Yazyev, A.J. Austin, R. Cammi, C. Pomelli, J.W. Ochterski, R.L. Martin, K. Morokuma, V.G. Zakrzewski, G.A. Voth, P. Salvador, J.J. Dannenberg, S. Dapprich, A.D. Daniels, O. Farkas, J.B. Foresman, J.V. Ortiz, J. Cioslowski, D.J. Fox, Gaussian 09, Revision B.01, Gaussian, Inc., Wallingford, CT, 2010.

[34] P.J. Stephens, N. Harada, ECD cotton effect approximated by the Gaussian curve and other methods, Chirality 22 (2010) 229-233.

[35] U. Varetto, MOLEKEL, v. 5.4, Swiss National Supercomputing Centre, Manno, Switzerland, 2009.

[36] A. Mándi, I.W. Mudianta, T. Kurtán, M.J. Garson, Absolute configuration and conformational study of psammaplysins A and B from the Balinese marine sponge Aplysinella strongylata, J. Nat. Prod. 78 (2015) 2051-2056.

[37] A. Mándi, M.M.M. Swamy, T. Taniguchi, M. Anetai, K. Monde, Reducing molecular flexibility by cyclization for elucidation of absolute configuration by CD calculations: daurichromenic acid, Chirality 28 (2016) 453-459.
[38] B. Tóth, E. Liktor-Busa, N. Kúsz, Á. Szappanos, A. Mándi, T. Kurtán, E. Urbán, J. Hohmann, F.R. Chang, A. Vasas, Phenanthrenes from Juncus inflexus with antimicrobial activity against methicillin-resistant Staphylococcus aureus, J. Nat. Prod. (2016) (accepted for publication).

[39] C.C. Shen, Y.S. Chang, L.K. Ho, Nuclear magnetic resonance studies of 5,7-dihydroxyflavonoids, Phytochemistry 34 (1993) 843-845.

[40] L.C. Lin, Y.F. Pai, T.H. Tsai, Isolation of luteolin and luteolin-7-O-glucoside from Dendranthema morifolium Ramat Tzvel and their pharmacokinetics in rats, J. Agric. Food Chem. 63 (2015) 7700-7706.

[41] D.H. Miles, J. Bhattacharyya, N.V. Mody, J.L. Atwood, S. Black, P.A. Hedin, The structure of juncusol. A novel cytotoxic dihydrophenanthrene from the estuarine marsh plant Juncus roemerianus, J. Am. Chem. Soc. 99 (1977) 618-620. 